\title{
The perception of experimentally induced failure'
}

\section{CARL H. CASTORE ANO SIEGFRIED STREUFERT ${ }^{2}$}

RUTGERS, THE STATE UNIVERSITY

A simulated decision making environment was used to examine the relationship between experimentally induced failure and $S$ serceptions of success and failure. The obtained relationship between induced and perceived failure was generally linear, with a significant higher order trend. The implications of the se findings for homeostatic and adaptation level theories of perception are considered.

Since level of failure is a rather common experimental manipulation, it would seem profitable to examine the relationship between the experimental manipulation of failure and Ss' perceptions of success and failure more closely. Frequently, Es have assumed a direct correspondence between experimentally induced failure and perceived failure (e.g., Atkinson, 1957; Mcclelland, Clark, Roby, \& Atkinson, 1949). However, available evidence would seem to indicate that the relationship could be thought of as linear only in a very general fashion, particularly under conditions of increasing failure or repeated exposure to the same level of failure. For instance, Shelley (1950) noted that there was little relationship between experimentally induced success and failure and Ss' perceptions of the degree of success or failure they had experienced. Further, the Ss in the success and failure conditions of his experiment could not be differentiated on the basis of their perceptions of experimentally induced success and failure.

Related research has shown that a non monotonic curvelinear relationship exists between induced success and failure and Ss' expectations for success or failure (e.g., Ford, 1963; Hilgard et al, 1940; Spector, 1956).

These findings suggest that Ss' perceptions of success and failure may show successive adaptations to the situation. Such a relationship would be predicted from the theoretical positions of Berrien \& Angoff (1957) and Driver \& Streufert (1965). This prediction is also paralleled by the findings of Miller (1960) with adaptation to increasing punishment. This experiment is concerned with a partial investigation of these propositions.

Subjects

The Ss used in this experiment were 14 male volunteers drawn from an introductory course in psychology Ss received payment and bonus credit toward their course grade for participation.

\section{Procedure}

Ss were placed in a tactical and negotiations game situation (a modification of the tactical game described in Streufert, Clardy, Driver, Karlins, Schroder, \& Suedfeld, 1965). They were given the task of making decisions regarding the direction of the diplomatic and tactical operations of a mythical foreign power engaged in subduing a revolution within a small country. Ss were under the impression that they were playing against other Ss representing the revolutionary movement. However, all functions of the enemy were performed by the Es. The strategy of the supposed enemy was preprogrammed. The constant stratezy and design of the mythical country assured that all Ss could be kept approximately equal in (a) the general kinds of operations which would be employed by them, (b) the types of failures which they would experience, und (c) the degree of failure which would be associated with the $S^{\prime}$ 's actions. Information load was held constant at 10 inputs per half hour session (cf., Streufert \& Driver, 1965; Streufert \& Schroder, in press; Streufert, Suedfeld \& Driver, 1965). Half of the inputs for each period dealt with diplomatic affairs and half with tactical matters. The order of the diplomatic and tactical inputs was randomly varied across periods.

All teams were exposed to 10 sequential levels of failure (i.e., $1,2,3, \ldots$, or 10 messages indicating failure). The number of messages communicating failure was increased sequentially from period 1 through period 10. The remaining messages for each period were neutral (i.e., contained relevant facts, but indicated neither success nor failure of operations). Failure was randomly varied across the tactical and diplomatic inputs for each period.

All 10 game periods were played in one evening. After each playing period was completed, Ss were instructed to fill out a "report to home country" form. (These forms were similar to the "commander reports" described in Streufert et al, 1965.) In this report, Ss were presented with two six-point scales on which they were to rate the degree of success and the degree of failure they had experienced during the preceding period. The data analysis is based on S' scores on these scales.

\section{Results and Discussion}

Since period 1 was used as a warm-up period to acquaint Ss with the experimental environment, the data from that period are not included in the analysis.

A within-Ss analysis of variance was used as a test of significance (Winer, 1962). There was no significant difference between ratings on the "inverted success" rid "failure" scales. Further data analysis was thereiore based on the failure scales. The main effect of level of failure was significant $(F=6.2258 ; p<.01)$. A trend analysis of the data indicated that the linear and quintic components were significant ( $F=16.9920$; $\mathrm{p}<.01 ; \mathrm{F}=5.8482 ; \mathrm{p}<.05$, respectively). Seventy-six percent of the variance was accounted for by these effects. 


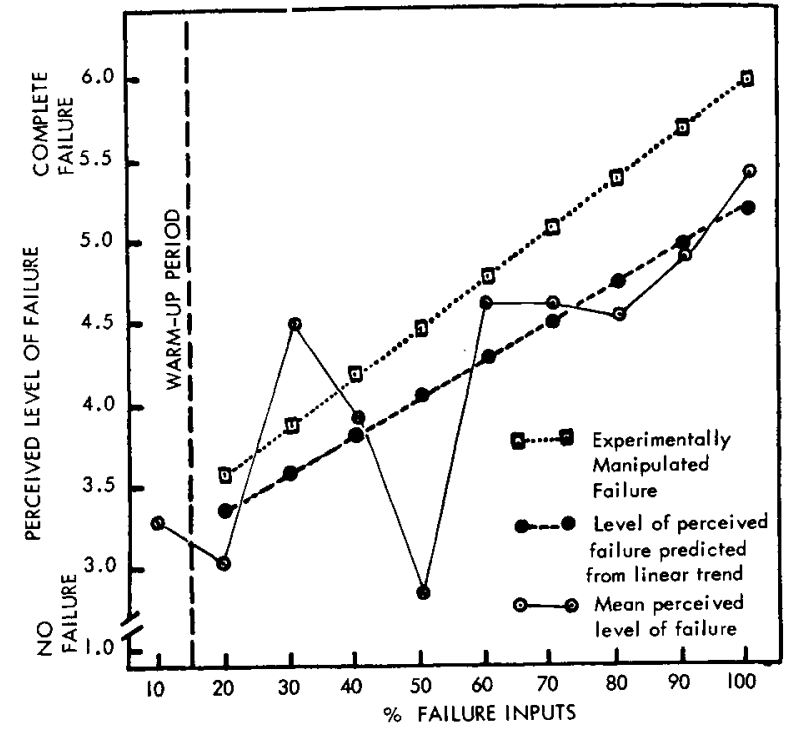

Fig. 1. A comparison of perceived and experimentally manipulated failure.

The mean perceived degree of failure at each level of induced failure is shown in Fig. 1. The differences between the means for adjacent levels of failure were compared using t-tests. ${ }^{3}$ The differences between levels 2 and 3,3 and 4,4 and 5,5 and 6 , and 9 and 10 were significant $(p<.05)$.

Taken together these results indicate that although the perception of failure increased in a generally linear fashion, there were significant deviations from linearity. Further, as can be seen from Fig. 1, although the Ss' perceptions of failure generally increased with increasing induced failure, the increase in perception was less than the experimental increase. These results are similar to those found by Miller (1960) comparing the effects of gradually increasing punishment to the onset of an initially high level of punishment.

There is little possibility that the obtained results were due to the passage of time alone. Previous research (Streufert \& Schroder, in press) has found no significant changes in perception of success or failure over time when the levels of experimentally induced success and failure were held constant. We may therefore conclude from the present data that there were two types of adaptation taking place: (a) A series of successive specific adaptations to particular quantities (i.e., proportions) of failure, indicated by the quintic trend, and (b) an apparent general adapta- tion of the Ss, indicated by the differences between manipulated levels of failure and perceived levels of failure expressed by the divergence of the linear trends in Fig. 1. The first type of adaptation could be predicted from the homeostatic model of Berrien \& Angoff (1957); the second from the anticipation-invigorationmechanism of Cofer \& Appley (1964). Both effects are predictable using the general incongruity adaptation level model proposed by Driver \& Streufert (1965).

\section{References}

Atkinson, J. W. Motivational determinants of risk-taking behavior. Psychol. Rev., 1957, 64, 359-372.

Berriern, F. K., \& Angoff, W. H. Homeostasis theory in small groups. New Brunswick, N. J.: Rutgers-The State University, December, 1957. Tech. Rep., contract Nonr 404 (10).

Cofer, C. N., \& Appley, M. H. Motivation: Theory and research. New York: John Wiley \& Sons, Inc., 1964.

Driver, M. J., \& Streufert. S. The "general incongruity adaptation level" (GIAL) hypothesis: An analysis and integration of cognitive approaches to motivation. Lafayette, Ind., Purdue University. Institute for research in the behavioral, economic, and management sciences paper no. 114.

Ford, L. H. Reaction to fallure as a function of expectancy for success. J. abnorm. soc. Psychol.. 1963, 67, 340-348.

Hilgard, E. R., Sait, E. M., \& Magaret, G. A. Level of aspiration as affected by relative standing in an experimental group. $J$. exp. Psychol., 1940, 27, 411-421.

McClelland, D. C., Clark, R. A., Roby, T. B., \& Atkinson, J. W. The effect of need for achievement on thematic apperception. $J$. exp. Psychol., 1949, 37, 242-255.

Miller, N. E. Learning resistance to pain and fear: Effects of overlearning, exposure, and rewarded exposure in context. $J$. exp. Psychol., 1960, 60, 137-145.

Shelley, H. P. The role of success and fallure in determining attitude toward the group as a means of group member goals. Ann Arbor, Mich.: University of Michigan, Conference Research, 1950.

Spector, A. R. Expectations, fulfillment and morale. J. abnorm. soc. Psychol., 1956, 52, 51-56.

Streufert, S., Clardy, M. A., Driver, M. J., Karlins, M., Schroder, H. M., \& Suedfeld, P. A tactical game for the analysis of complex decision making in individuals and groups. Psychol. Rep., $1965,17,723-729$.

Streufert, S., \& Driver, M. J. Conceptual structure, information load, and perceptual complexity. Psychon. Sci., 1965, 3, 249-250.

Streufert, S., \& Schroder, H. M. Conceptual structure, environmental complexity and task performance. J. exp. Res. Pers., 1965. in press.

Streufert, S., Suedfeld, P., \& Driver, M. J. Conceptual structure, information search and information utilization. $J$. Pers. soc. Psychol., 1965, 2, 736-740.

\section{Notes}

1. This research was supported by the Research Council, Rutgers, The State University.

2. Douglass College.

3. Tested with the Scale by Level of failure by ss error term having 104 degrees of freedom. 